\title{
ARTICLES \\ Defensive over Climate Change? Climate Shame as a Method of Moral Cultivation
}

\section{Elisa Aaltola ${ }^{1}$ (D)}

Accepted: 23 January 2021 / Published online: 27 February 2021

(c) The Author(s) 2021

\begin{abstract}
The climate crisis is an enormous challenge for contemporary societies. Yet, public discussions on it often lead to anger, mocking, denial and other defensive behaviours, one prominent example of which is the reception met by the climate advocate Greta Thunberg. The paper approaches this curious phenomenon via shame. It argues that the very idea of anthropogenic climate change invites feelings of human failure and thereby may also entice shame. The notion of "climate shame" is introduced and distinguished from "climate guilt". Whereas climate guilt prioritises the flourishing of the environment and is focused on actions and morality, climate shame is concerned with human identity and selfhood. The paper then explores whether shame is a morally destructive or constructive emotion. Making use of both psychological and philosophical literature on shame, it argues that although shame faces many challenges that question its usefulness in moral pedagogy, these challenges can be met with "moral maturity"-moreover, following a utilitarian approach, the overall benefits of climate shame can justify its costs to individuals. My argument is that climate shame holds the potential of being a highly effective moral psychological method of persuasion, capable of inviting wholesale critical reflection on current, environmentally damaging practices and cultivation of more virtuous ways of co-existing with the rest of the natural world and other species.
\end{abstract}

Keywords Environmental ethics $\cdot$ Climate change $\cdot$ Moral psychology $\cdot$ Shame Guilt

\section{Introduction}

Shame is a difficult emotion in various ways. It is challenging to define comprehensively and there is debate over its moral consequences. It is painful, even excruciating to fall into its hold. Yet, we may need shame, or at least the ability to come to

Elisa Aaltola

elanaa@utu.fi

1 University of Turku, Turku, Finland 
terms with its at times disquieting existence, in order to improve our moral ability. This applies also in the context of everyday environmental ethics.

The challenge of climate change (or more accurately, "the climate crisis") can, on the moral psychological level, enmesh with shame. The emergence of Greta Thunberg manifests poignantly the links between the climate crisis and potential shame. Her rationally articulated blows to both corporate and political decision-makers and consumers have sparked a curious phenomenon: adult men hurling insults at a 16 year-old girl, publicly attacking her looks, intelligence and autism. Thunberg has been met, on occasion, with rage void of rational content, her motives have been questioned, and conspiracy theories have surfaced to explain away the serious message of her arguments. Examples of the belittling fury directed at Thunberg are numerous. They include a commentator on Fox News calling Thunberg "a mentally ill Swedish child", the Fox News host Laura Ingraham referring to Thunberg as she states: "I can't wait for Stephen King's sequel, Children of the Climate", and Donald Trump labelling the naming of Thunberg as Time's Person of the Year as "ridiculous". ${ }^{1}$ They also include the US treasury secretary Steven Mnuchin suggesting, in a condescending tone, that Thunberg should first go to college and become an economist before airing her views. ${ }^{2}$

Something quite peculiar is going on, and Thurnberg is only the tip of the iceberg when it comes to the fury met by those, who publically speak of the current environmental catastrophe. Talk of the climate crisis is frequently met with irrational hostility, which in itself is becoming a distinct societal phenomenon. One glue to what is at the core of this phenomenon is found from a statement given by a former member of the Nobel Peace Prize Committee, which ultimately chose not to award Thurnberg with the Nobel Peace Prize in 2019. The member, Sverre Lodgaard, claimed that: "The problem is that the principle of 'flight shame' brings her chances ... down. Shame is not a constructive feeling to bring about change". ${ }^{3}$ In short, Thunberg sparked shame in given others, which again led to anger and resistance against her. Indeed, Thunberg has explicitly shamed the powers to be, most famously in her 2019 speech at the UN, where she told the world leaders: "You are failing us" and "How dare you". ${ }^{4}$ She has also implicitly caused shame in ordinary individuals over their environmentally questionable practices, for instance by making public her decision not to fly. This decision has been positioned as the momentum behind the phenomenon mentioned above- "flight shame" (flygskam in Swedish) — which is widespread enough to be perceived as a major threat by the airline industries. ${ }^{5}$ Hence, Thunberg can spark shame also unintentionally, with nothing more than her own, morally considered actions. As will become evident, already the

\footnotetext{
1 https://www.vox.com/2020/1/23/21078848/greta-thunberg-steve-mnuchin-trump-time-activist.

2 https://www.bbc.com/news/business-51219530.

3 https://www.reuters.com/article/us-nobel-prize-peace/a-nobel-for-swedens-greta-thunberg-a-tough -decision-for-prize-committee-idUSKBN1WA18Z.

${ }^{4}$ https://www.theguardian.com/environment/2019/sep/23/greta-thunberg-speech-un-2019-address.

5 https://www.latimes.com/business/story/2020-02-07/flight-shaming-airlines-climate-change-greta -thunberg.
} 
fact that Thunberg draws significant attention to environmental concerns can spur shame in some. Therefore, regardless of whether she and other climate advocates intentionally wish to cause it, shame seems to follow discussions on climate change.

It is not difficult to see, how talk of anthropogenic climate change may ignite shame-after all, we are all implicated to a lesser or greater degree. Members of Homo sapiens have committed actions with ruinous consequences to other species and environmental systems. Of course, particularly those with affluence, privilege and power are to blame, and many indigenous peoples have sought to remind those in the West of the urgent need to respect nonhuman nature. ${ }^{6}$ Yet, also the prehistory of our species is coloured by the over-use of natural resources (Harari 2014), which suggests that there is an inclination, too often rendered actual, within us to treat the nonhuman world selfishly and unwisely. In this sense, we have failed, and if our lifestyles are invested in high consumption and the prioritisation of economic or personal benefit at the expense of environmental values to an extent that we identify as "consumers", "fliers", "meat-eaters", "business leaders" or "leading politicians", that failure is evermore evident. Therefore, anthropogenic climate change, and more broadly the destruction caused by the Anthropocene to other species, come with a sense of deep failure at the core of who we are (our identity or selfhood). These are the stereotypic ingredients of shame: failure, identity and selfhood (Gausel and Leach 2011; Tangney 1995; Taylor 1985).

Coming to terms with the climate crisis may, then, require that we come to terms with shame. The paper gains its impetus from here. It (1) explores the relation between morality and shame: does shame hinder or better our moral agency?, and (2) introduces "climate shame" as a concept that may facilitate the sort of moral awareness and development that allows us to finally deal adequately with the climate crisis. The paper also seeks to highlight how climate shame places most pressure on those with most social, political and economic power. In addressing these issues, it makes use of both psychological and philosophical research on shame and applies it to everyday, de facto environmental ethics (how we in practice value and treat the nonhuman world). ${ }^{7}$ There is hardly any philosophical or moral psychological research on the potential role of shame in curtailing climate change-a surprising lapse that the article hopes to address.

\section{Climate Guilt and Climate Shame}

In both psychological and philosophical research literature, guilt and shame are often carefully distinguished. There appear to be at least four points of difference between the two. First, whilst guilt remains other-directed and is concerned with

\footnotetext{
6 See for instance https://www.theguardian.com/commentisfree/2020/oct/12/western-worldyour-civilisati on-killing-life-on-earth-indigenous-amazon-planet?

7 This paper presupposes that constructive environmental ethics (values, norms and related actions concerning the environment) seek to support the flourishing of the nonhuman world and to preserve its richness.
} 
the violation of others' wellbeing, thus focusing on what the consequences of our actions have been for the external world, shame is self-directed and focused on the consequences we, ourselves, may undergo (Lewis 1971).

Second, whereas guilt concerns actions, shame revolves around one's selfhood: in a state of shame, we are not so much preoccupied with what we have done, but who we are. In L'être et le néant, Jean-Paul Sartre has offered a classic description of shame with his keyhole example, in which a voyeur is gazing through a keyhole only to suddenly realise that he himself is being looked at by someone standing behind him (Sartre 1993). The voyeur has lost his subjectivity and become an object of a critical other, which is often taken to form the core of shame. This can be interpreted to mean that in a state of shame, one's sense of agency is diminished or altogether erased, which again, since in Western philosophy selfhood is standardly characterized via notions of active agency, erodes one's selfhood. One becomes a defunct lump of flesh, void of a capable "self", a hapless, naked, faulty object. What we are, our ontological status, is shown to be defective.

A more contemporary analysis of the connection between shame and selfhood comes from David Velleman, who has argued that shame is born when private becomes public without consent. According to him, one's ability to govern both one's private realm and its relation to and borders with public existence is necessary for a sense of agency. We need to be able to direct which aspects of our lives remain private, and which are rendered public. When the private realm is made public against our will, our agency is nullified, which again pushes us to the anguishing clasp of shame (Velleman 2001). In a state of shame, our agency and thereby our selfhood is questioned, and this more than anything reduces us to Sartrean objects. What renders shame particularly agonizing is the globalizing aspect many scholars attribute to it. Shame does not concern only one part of one's "self", but "the self" in its entirety (Teroni and Bruun 2011). Psychological studies have manifested that individuals find describing shame more difficult than describing guilt, which again has been taken to mean that shame is a more integral, holistic emotion impacting one's whole being (Tangney 1992). In short, shame is too all-consuming, too capable of eroding who "we" are, to be easily defined.

The third distinguishing factor is that whilst guilt entwines with one's own internal evaluation of the situation ("I have committed a moral wrong"), shame stems from external evaluation ("They think that I have messed up"). A person may feel guilt even when nobody knows of her transgression (internal evaluation suffices), and thus Raskolnikov from Dostoyevsky's Crime and Punishment broods over his murderous deed long before he is discovered. On the other hand, a person who does not think she has done anything wrong may feel shame simply because others judge her (external evaluation suffices). Bernard Williams has exemplified this distinction with a sensory metaphor. In the grips of guilt, one hears the voice of one's conscience, and in the pains of shame, one sees the critical gaze of others (Williams 1993). Indeed, shame is often characterised as a deeply social emotion, which requires an outside audience who views us critically, and in philosophy, this social aspect of shame is so commonly brought forward that exceptions are arduous to come by. For instance John Deigh and Dan Zahavi have argued that in a state of shame, we momentarily believe the critical 
evaluation concerning ourselves, formed by another (Deigh 1983; Zahavi 2010). The inner depiction of our "selves" is interrupted by outside critical assessment, which leaves us suddenly certain that "the self" is utterly flawed.

This observation gains substantial support from psychology, and for instance June Tangney, who has studied shame extensively, underlines its social nature (Tangney 1992). In fact, shame has been positioned as one of our earliest social emotions. The psychologist Paul Gilbert is among those, who have highlighted how selfhood is inherently related to the yearning for social acceptance (Gilbert 2003). As social animals, human beings form their self-conception partly on the basis how others respond to them, and are continuously seeking for positive validation that signals social inclusion. For a social creature inherently on the lookout for approval and connection, rejection can feel unbearable (Pinto-Gouveia and Matos 2011). As a result, we learn to abhor exclusion and thereby stay in the group, which-on a savannah roamed by lions or a megapolis filled with poverty-can be a matter of survival. It is therefore functional to undergo unpleasant feelings, even horror and despair, when faced with criticism and disapproval, for they make us avoid the things that could lead to rejection and exclusion. Following suit, one suggestion is that that shame serves an evolutionary function by engulfing us with distress when others condemn us. Even defensive behavior such as hiding from others, often linked to shame, can serve this function-when we withdraw from the social group, we gain time to reconsider our actions and alter ourselves so as to become more acceptable to others (Tangney et al. 1996).

Yet, social judgment and rejection need not be actual. Gabriele Taylor and Krista Thomason have claimed that an imaginary audience suffices for shame. Thereby, even if we merely imagine another evaluating ourselves critically, shame may arise (Taylor 1985; Thomason 2015). This has been linked to the internalization of socially shared norms and values, whereby they gain the internal manifestation of an external judge. Indeed, sociologists studying shame have argued that it interlinks with the tendency to adopt social norms and identities in one's yearning for acceptance. Shame can push us toward ever-greater adaptation to social expectations-its pained, raw nature keeps us in line with external, in-group standards (Stets and Carter 2012). Again, Sartre emerges as relevant, as one can hear echoes of existential philosophy and "bad faith" in the act of unguardedly internalizing social norms and becoming prey to their critical power; in an interesting twist, one's social nature in itself exposes us to become ashamed objects.

The fourth (and related) difference between guilt and shame, put forward in literature, is morality. Thomason is among those, who have argued that whilst guilt stems from moral violations, shame may be wholly amoral, originating from social rather than moral damage. Indeed, as a consequence of its break from morality, shame can lead to immoral behaviours (Thomason 2015). Guilt revolves around moral beliefs ("I should not have done x") and motivates restitutive actions, whereby we seek to mend what we have broken, whilst shame can be sparked by nothing more than social disapproval over something morally irrelevant (such as one's physical appearance), and feed obviously immoral actions, such as violent rages (Covert et al. 2003). 
Therefore, guilt and shame differ via the following dichotomies: other-directedness-self-directedness, action—selfhood, internal evaluation-external evaluation, and morality-social esteem. These dichotomies offer a convenient way to approach guilt and shame also in the context of everyday environmental ethics. Applying the above literature, what is here called "climate guilt" concerns environmentally relevant and harmful actions or action-tendencies, such as unnecessary flying and driving, consumption of red meat, high consumerism, and the overall inclination to favour fossil fuel based or otherwise damaging practices. Climate guilt can also stem from participating in an environmentally damaging economy and political system without protest, following the models of consumerism set by it. Its orientation is toward the natural environment and how one's actions impact it, and thus an individual may feel intense pangs of guilt when seeing news coverage of wild fires or famished polar bears roaming for food. Following suit, instead of focusing on what others think of her or what her identity is, the person in the grips of climate guilt will-in the best scenario described by the above literature-focus on and change her actions and action-tendencies. Furthermore, climate guilt originates from one's internal norms, whereby the individual undergoing guilt recognizes that she is doing something wrong regardless of what her social surroundings tell her-indeed, she may for instance carry guilt over meat-eating even if societal values advocate carnivorous tastes. Finally, climate guilt concerns morality, the "right" and "wrong" of how human beings ought to treat their surrounding world.

There is limited research on the relation between guilt and climate change. It has been noted that guilt acts as one potent emotional incentive behind the animal rights movement, motivating action on behalf of nonhuman creatures (Jacobsson and Lindblom 2016). One may take this to imply that also environmental action utilizes guilt. Yet, according to one study, some climate activists are eager to shun guilt. Interestingly, the issue depends on the cultural context. People in the Global North tend to avoid causing and feeling guilt in regard to climate change, whereas individuals in the Global South are more prone to place guilt (particularly and understandably on the northerners). This difference has been used to partly explain why the Global South are more politicized over the issue of climate change (Kleres and Wettergren 2017). It has been hypothesized that the shunning of guilt can lessen climate advocates' political efficacy in the northern regions, particularly due to lessening the anger often associated with notions of blame and guilt (we frequently get angry at those, who are guilty) (Kleres and Wettergren 2017). There is further support for the notion that northerners are less comfortable with guilt, with negative implications from the perspective of moral change. A study, which explored Norwegian attitudes to climate change, noted how guilt is avoided or controlled, which correlates with the refusal to alter one's actions (Norgaard 2011). In sum, those who are most to blame (people in the Global North) are most likely to view guilt as unproductive and less likely to change their actions. This supports the above definition of climate guilt: it motivates moral reflection and corrective action. More broadly, one can take all this to imply that we need climate guilt (recognition of it in both ourselves and others) in order to instigate political change in the environmental context.

Climate shame, on the other hand, is quite a different phenomenon. The ashamed orientates toward her own wellbeing: what does the criticism of anthropogenic 
climate change mean from the viewpoint of her own dietary habits or financial gain? Also, the ashamed is not primarily worried about given actions but instead focuses on her "selfhood", pondering what the implications of the discussions over climate change are for her self-image. What does the discussion and criticism mean from the perspective of who I am as a person? Furthermore, such shame originates primarily from external criticism, and thus the simple act of being under criticism, even in the absence of internal acceptance of that criticism, can flood one with intense climate shame: thus, Greta Thunberg can provoke shame also in individuals, who do not believe in anthropogenic climate change. Finally, climate shame revolves more around the social rather than moral dimension. Instead of moral issues, what surfaces as pivotal is the key question of most members of Homo sapiens: do others like me or not? This question can have deep affective and practical meaning, signaling whether we are socially accepted and included or not.

It is not difficult to note how environmental advocates such as Thunberg may have aroused climate shame. Particularly those individuals, who traditionally have retained considerable volumes of power and wealth, are suddenly placed under critical, external evaluation, which questions their very ideologies, self-centered ways of being and acting in the world, and ultimately social identity. In short, given social groups — such as affluent consumers, politically powerful individuals, and industry leaders-are most poignantly at the receiving end of criticism, which means that their self-interests, together with their social identity and "selfhood", are under attack. This is perfect soil for shame to grow in. ${ }^{8}$ The very act of being under critical, public scrutiny can seem intolerable, even when the ashamed do not share the environmental values of Thunberg (and may even deny the existence of climate change).

Now, the crucial question for our present purposes concerns the last of the breaks between guilt and shame. Since shame has been linked to social approval rather than morality, does climate shame not mean that, for the ashamed, ethical concerns regarding the environment remain irrelevant? In other words: is climate shame a harmful or a productive emotion when it comes to morality? Does it help us to recognise environmental values and adjust our actions accordingly, for instance by making us significantly lessen climate emissions, consumerism, meat-eating, and other factors, which are currently threatening the survival of a multitude of species?

\footnotetext{
8 Thunberg's case is particularly noteworthy, since she is fundamentally "external" to many of those, whom she criticizes - a young female with autism is daring to publically question instances with a lot of affluence and political power, whom are often older, neurotypical men. Thus, it is interesting to notice the demographic background of those, whom have attacked Thunberg the loudest, for it reveals how social identity possibly impacts the situation. Indeed, next to shame, also gender politics may influence the reception Thunberg receives, as powerful men appear to find it difficult that a young female is vocally criticizing them.
} 


\section{Morally Destructive Shame}

Guilt enhances moral agency, as it allows one to recognize problems in given actions, evaluate those actions from the perspective of others, and amend one's behavior in the future. Indeed, empirical studies show that guilt-proneness correlates positively with ethical decision-making, whilst some instances of shameproneness correlate positively with unethical decisions (Cohen et al. 2011; Tangney et al. 2011). This has been explained via guilt's connections to empathy and behavior evaluation: guilt entwines with concern for others' perspective and moral evaluation of actions, whilst shame-proneness lacks these qualities (Poless et al. 2018). In light of this, climate guilt surfaces as a morally constructive emotion, capable of making us aware of the mistakes in, say, overuse of fossil fuels and animal-based foods, and able to motive us to do better in the future. Climate shame, on the other hand, does not appear to come with morally fruitful implications (it does not seem to enhance moral agency or one's willingness to make choices that support nonhuman flourishing). From this perspective, the individuals fuming at Thunberg are not reconsidering their attitudes toward the environment-quite the contrary, many give the impression of being evermore vehement in their denial of environmental values.

This impression falls in line with one variety of shame research, which depicts shame as a morally destructive emotion-an emotion that erodes moral agency. How could individuals, who are preoccupied with self-interest whilst feeling incapable, despondent and ridiculous pieces of flesh alienated from moral issues, become more rather than less morally capable? One common argument is that particularly the global nature of shame adds to its break from morality. If one's whole "self" is a failure, nothing can be done, no efforts to become more moral can change the wretched situation-all hope is lost, and one can only choose despondency when it comes to morality (Allpress et al. 2014; Tangney 1995). The negative view of shame's moral potential is buttressed by shame's connection to psychological defensiveness. As Tangney and others have argued, whereas guilt tends to spark apologies and afore-mentioned reconciliatory behaviours, shame is more likely to fuel counterproductive defenses and despair (Tangney 1995; Martens 2005; Gilbert 2003). Applied to everyday environmental ethics, this would mean that climate guilt can feed the eagerness to take action on behalf of nonhuman nature and change those practices that cause harm, whilst climate shame leads to anguished defensiveness-something that at least some of the insults hurled at Thunberg appear to attest to (although of course one cannot know the real psychological motivations in each case).

The cause of such defenses is simple and can be located to the affectively painful nature of shame. Shame can feel tortuous. Simone Weil has argued that the most intense form of suffering or what she terms "affliction" is caused by a sense of complete failure as "a self" (Weil 2002). Indeed, studies suggest that the affective dimension of shame includes feelings of smallness, worthlessness and powerlessness, which render shame a much more agonizing emotion than guilt (Gramzow and Tangney 1992; Tangney 1995; Tangney et al. 1996). It would seem that 
the torment integral to shame involves two elements. First, as suggested above, it can feel extremely painful for social animals to undergo a sense of rejection by the group - a connection to others, so vital for wellbeing - is broken. Second, since shame places the adequacy and even existence of our selfhood under question, it can feel like an annihilation of "the self"- - something that Weil refers to. If the feeling of complete inadequacy sparks nothing short of anguished horror, one's mind quickly seeks to escape shame via defensive routes in order to restore a more tolerable state.

Psychological literature has mapped out various typical defensive behaviours associated with shame. First, there is withdrawal from the causes of shame, i.e. other individuals. The ashamed person may evade the critical evaluations of others by avoiding either specific, shame-provoking individuals or groups, or (in the extreme) other humans in general. She may also seek to hide her shame-evoking transgressions or characteristics (Allpress et al. 2014; Sheikh and Janoff-Bulman 2009; Lickel et al. 2005; Gausel and Leach 2011; Tangney et al. 1996; Tangney 1995). Whichever the level of withdrawal, the logic is obvious: to shield oneself from the criticism of others by becoming more or less undetectable. The common, tangible urge to hide one's face and vanish under the floorboards is, from this perspective, a defensive action against shame. Yet, withdrawal can also manifest in one's desire to push the societal gaze under those floorboards. Indeed, the philosopher Johann Klaassen has argued that the avoidance of shame takes also the form of loudly forsaking the social values or norms, which cause shame. In the extreme, this may feed eccentric, provocative behavior, as the ashamed boasts of her insolent disregard for social conventions (Klaassen 2001).

Another common form of defense discussed in research literature is anger or downright fury. Of course, anger is not always a result of shame, and individuals can be furious for other, quite justifiable reasons. However, it is possible that anger is stirred by shame. Instead of withdrawing from those, who cause shame, this defense leads one to attack them either mentally or (in the rarer cases) physically. Anger may also be turned against oneself, as the ashamed hates and punishes herself for having been shameful (Nazarov et al. 2015). Anger toward others and oneself can form causal connections, as self-hate can transform into hate of others (Lewis 1971), whereby the ashamed projects her own failings onto others, and in a loathing voice declares that they are the ones, who are defective individuals. Whichever form hate, anger and aggression take, they alleviate shame by reconstructing one's sense of agency. In this vein, Thomason has posited that anger is a method of restating one's agency_raging at another may spark a sense of potency and activity, which counteracts the agonizing loss of selfhood implied by shame (Thomason 2015). However, the regaining of one's agency may be only momentary and superficial. In her studies, Tangney has found that shame and anger are often so integrally related that they can lead into shame-rage-spirals, where shame provokes anger, and anger again worsens one's shame (Tangney 1995; Klaassen 2001).

Also climate shame can spark defensiveness, which appears to question its moral constructiveness. If environmental values cause shame in a person, she may seek to avoid individuals and instances that remind her of those values and simply turn the other way, when climate change is mentioned. She may also retaliate by explicitly 
denouncing environmental values, loudly manifesting that she simply does not care (indeed, in 2019 the British journalist Julia Hartley-Brewer tweeted in reference to "flight shame", seemingly confusing guilt and shame: "Hi Greta, I've just booked some long haul flights for my family to enjoy some winter sun on the beach this Christmas. Level of guilt being felt: $0 \%$ ", ). A further, manifestly popular option is to downplay the relevance of climate science and even deny the existence of anthropogenic climate change, which at times combines with references to conspiracy theories. The ashamed can also turn toward anger and start either scolding herself or attacking those, who speak of climate change. When the greta thunbergs of the world criticize one's lifestyle and ideology, one obvious route out is to attack the thunbergs back by mockery, aggressive name-calling and public bullying, whereby one's sense of agency is (at least momentarily) restored. Again, it should be emphasized that not all withdrawal or anger are signs of shame. However, shame is one possible explanation for them; in case of Thunberg, powerful individuals may feel embarrassment or shame already due to the fact that a young girl is publically criticizing them. The implication appears to be that it is best to avoid causing shamealso when it comes to issues such as the climate crisis-for shame will only spark destructive defenses.

Further indicators of shame's poor consequences from the perspective of moral ability are found from its connections to various mental disorders and poor psychological wellbeing. According to a common claim, shame is integral to the narcissistic personality disorder, and may in fact be the reason why highly narcissistic individuals cannot cope with criticism, act in a grandiose manner in order to enhance their selfhood, and act out in rageful ways when evaluated critically (Gramzow and Tangney 1992). Shame has also been correlated with eating disorders (Troop et al. 2008), depression (Andrews et al. 2002), anxiety disorders, trauma-related anxiety, and dissociation (Irwin 1998; Tangney 1995; Gilbert 2003; Pinto-Gouveia and Matos 2011). In line with the above defenses, shame also correlates positively with self-hate and low sense of self-worth (Gilbert et al. 1996), which again diminish psychological wellbeing. Chronic shame has also been linked to childhood traumas, whereby a person learns to interpret herself and her surroundings with negativity, convinced of her own inadequacy and the untrustworthiness of others (Pinto-Gouveia and Matos 2011; Irwin 1998). Another association has been found from social subjugation and related depression: when an individual is involuntarily subjected to domination, she may begin to feel low self-worth, powerlessness, inadequacy, loss of agency, and other negative traits included in shame (Gilbert 2000). ${ }^{10}$ Whatever its causes, proneness toward shame in general has been connected to poor mental health and functioning (Cohen et al. 2011), including difficulties in self-governance (Martens 2005), low activity, poor life-decisions and pessimistic expectations (Covert et al. 2003).

\footnotetext{
9 pic.twitter.com/BVE3JyiNgi.

10 This explains why mistreated people such as rape victims can undergo shame - even though the transgressors should fall into the grips of shame, it is their victims who often do the falling (Maibom 2010).
} 
These considerations add to the case against climate shame. Perhaps those individuals, who already struggle psychologically, are most prone to shame also in the context of environmental matters. Could it be that among the powerful individuals attacking Thunberg are also those, who struggle with narcissism and are thereby more disposed to undergo shame and retaliate with fury? Do psychologically painful events such as traumas expose already vulnerable individuals to climate shame in a manner that further harms their wellbeing? In both cases, psychological fragilities can magnify climate shame in a disproportionate fashion. The afore-mentioned social subjugation makes matters even more complicated, as it is possible that groups, which are already most disenfranchised, are also most likely to undergo climate shame, and least able to handle it constructively. Hence, both those with abundant power, and those with none, are fertile ground for shame's more painful effects.

Therefore, shame appears to come with troubling consequences from the viewpoint of morality. First, it seems to harm rather than promote moral agency. How could an emotion, which leads to withdrawing or aggressive defenses, and which can cause and entwine with mental disorders that further debilitate one's agency, possibly help one to become better at morality? Indeed, from this perspective, shame emerges as an emotion that feeds vices (such as unnecessary violence), and which no morally wise person would thereby intentionally cause in another in order to educate them in morality. Second, it may even seem that causing shame is, in itself, a moral wrong due to the immense suffering and hardship shame can cause-in fact, one could even speak of the duty to avoid causing shame in others.

As it comes to climate shame, the lessons seem straightforward. Shaming individuals or companies (as groups of individuals) on account of their environmentally destructive behavior appears counterproductive, for they may become defensive and their agency and thereby ability to better govern and direct their behavior in the future is potentially diminished. Instead of more environmentally virtuous individuals, one will find angry, self-hating people in less control over their moral decisions. Moreover, such shaming could directly harm individuals by exposing them to suffering and even mental health problems. Following this line of thought, the implication would be: no shaming when it comes to climate change.

However, this leads to a perplexing situation. If guilt does feed moral change and restitutive actions, whereby climate guilt could come with positive implications and enhance our ability to face the challenges of the climate crisis, how can one cause guilt without spurring shame? Should Greta Thunberg, climate scientists, or other relevant parties speak in a given manner in order to avoid causing shame? One solution can be found from the very definition of guilt and shame. If guilt concerns primarily actions and shame concerns primarily identity or selfhood, speaking of environmental issues with reference to actions (flying is bad) rather than people (fliers are bad individuals) can be of help (Aaltola 2016). Yet, the situation is more complicated. Williams suggests that each action can be interpreted either from the viewpoint of what happens to others, or from the perspective of what we, ourselves, are like (Williams 1993, p. 91). Which the dice falls on is a contextual matter, dependent on our own background and personality. In light of empirical research, it can be claimed that a shame-prone individual will hear personal criticism where a guiltprone individual will hear criticism of actions (Tangney 1992,1995). This highlights 
the contextual nature of whether one undergoes guilt or shame when faced with the climate crisis. One cannot pre-eliminate either emotion-the possibility of shame, therefore, is ever-present.

Fortunately, this may not be quite as a negative consequence as implied by the above literature. Indeed, there are also those, who think that shame is a morally productive rather than destructive emotion.

\section{Morally Constructive Shame}

Not all agree with the claim that shame is bound to lead us to moral despondency, irrational defensiveness and poor mental health. First, as it comes to the primacy of selfhood, it need not exclude morality. In fact, perceiving faults in one's "self" and taking part in negative self-evaluation can be of immense moral benefit. Critical self-reflection is necessary for moral cultivation, as it allows us to notice points that require improvement, and shame can act as its catalyst: in a state of shame, we recognise our failure to live up to our moral ideals, and wish to amend the situation. ${ }^{11}$ As Thomason and Taylor have underscored, shame is a result of a discrepancy between our social identity and self-conception: in the grips of shame, we suddenly note that we appear to others differently than we think of ourselves privately (Taylor 1985; Thomason 2015). Yet, this discrepancy holds obvious moral potential, for it may motivate us to live up to our own moral ideal.

Even global evaluation of "the self" need not be morally worrisome. John Wilson suggests that precisely because shame makes us feel as if our whole being is somehow faulty, it also invites wholesale, holistic cultivation. From this angle, it is even more effective than guilt: whilst guilt makes us change one action or habit, shame may push us toward changing our entire outlook on the world (Wilson 2001; Ferguson et al. 2007). Also Williams highlights the manner in which shame may entice us to rethink what type of creatures we wish to be in relation to the external world, and thereby invites comprehensive efforts of cultivation (Williams 1993). The logic of the argument is this: when we recognize our "self" to be faulty, we wish to alter that self, which leads to wide-ranging change in our constitution. Whilst guilt holds the power to provoke alteration in one specific belief, value or action, shame can cause more profound and systemic modification concerning entire systems of beliefs, values and actions.

In relation to everyday environmental ethics, this difference has obvious implications. Guilt can guide one to fly less, buy less, or eat less red meat, but shame can provoke one to question one's wider relationship with the natural environment. What is "humanity" and its relation to the rest of the world? What is the relation between "the human self" and non-human beings and entities? Why do I define my "self" in a particular way, and how does this impact how I treat the world around me? How could I define myself differently, so as to manifest a more respectful way of

\footnotetext{
11 Following suit, empirical studies show that highly narcissistic individuals lack the ability for negative self-evaluation, which again may partly explain their unethical decisions (Poless et al. 2018).
} 
co-existing with other species and natural entities? How should I change my beliefs, values and actions so as to be a more morally thoughtful person in regard to the rest of nature? Climate shame can teach us to interlock our selfhood with our environmental ethics, whereby how we value and treat the non-human realm reflects who we are as people.

This, surely, is a phenomenon far overdue. Arguably, the dualistic take on nature, common in Western cultures, has led to an impression, according to which nature is "out there" and actions toward it are morally irrelevant-environmental ethics is far removed and externalized from our self-conception. This, again, allows us to ignore and downplay moral concern for the environment. Climate shame can unravel this dualism and highlight a new ontology-one, where we define ourselves partly via how we treat the rest of nature. It is difficult to think of another emotion, which could spark such fundamental questions and thereby shake the very core of the sort of anthropocentric thinking, which emphasizes human and individual liberties (the freedoms of the "human self") at the cost of the natural environment. In short, how we tend to define our "human self" and its relation to the surrounding world is in dire need of a radical reconfiguration, and climate shame can be one catalyst that motivates such change.

Second, the social aspect of shame need not mean that morality is overlooked. In fact, as already Plato and Aristotle argued, precisely this aspect can teach us morality. In Gorgias, the judgment posed by others plays a role in our understanding of virtue (Gorgias 475b8-d4). In Nicomachean Ethics, Aristotle posits that shame holds pedagogic power, for it deters young people from committing shameful vices, and guides them toward virtue (NE1128b; see also Fussi 2015). Also Thomas Aquinas argued that shame teaches us virtue precisely because we do not wish to lose face in the eyes of others (ST II, Q144). According to these classic authors, instead of destabilizing one's moral compass, the social dimension of shame strengthens it by acting as a pedagogical tool. In line with the above-mentioned evolutionary function, shame deters us from actions that spark external judgment and thereby teaches us the ethics of our community.

This stance is common also in contemporary philosophy. For instance Heidi Maibom and Bernard Williams argue that the social aspect of shame facilitates moral learning. From the perspective of shared, communal values, it is necessary to pay heed to what other members in our social environment think of us (Maibom 2010; Williams 1993). Here, Williams criticizes an internalist understanding of morality, which posits that one's own internal evaluation suffices for morality. Following the footsteps of Greek philosophers, he claims that morality by necessity requires feedback from others - its mechanisms rests on sociality (Williams 1993). Therefore, what the existentialist critique views as loss of freedom and herd-like internationalization of social norms, can also be depicted positively. Morality is learned from the surrounding social world, and internalization of norms is thereby a requirement of moral agency. Of course, the idea is not to simply accept any external evaluation or social norm as "the truth", which would — as Taylor posits-lead into a state of confusion and conformation (Taylor 1985). There still exists a difference between "bad faith" and openness to social feedback. Whereas the former makes us follow norms without further reflection, and urges us to adhere, for instance, to conservative takes 
on gender and sexuality, the latter can, in its most productive form, combine internal analyses of moral issues with social learning.

In light of the above, shame emerges even as a pivotal moral emotion, and the capacity to undergo and learn from it a necessity for one's moral agency. This idea finds support from also empirical studies, as shame can guide our conceptions of what is acceptable behavior (Gilbert 2003). The positive stance toward shame has been evident in harsh practices from the past, such as the pillory, which have publicly shamed individuals so as to signal what is inexcusable in the society. Also contemporary cultures - intentionally or unintentionally-use shame as a pedagogical tool, the obvious example of which are public exposures such as the \#metoo-campaign, which aim to communicate moral boundaries and values by shaming given individuals.

Also climate shame can serve as a social pedagogic tool by teaching us important, (at least to some extent) socially accepted norms concerning the environment. Here, the power of shame is two-fold. First, it acts as a preventive emotional measure in matters relevant to environmental ethics. Feeling shame over the climate crisis can, on the individual level, steer us away from airports and frequent visits to shopping centers, and on the corporate level limit the use of fossil fuels and lessen the hunger for material resources. The more widely accepted the relevant environmental values and norms are, the more potent the preventive force of shame: if flying or meat-eating were rendered into deeply shameful acts, getting into a plane or digging into a steak would most probably become rare exceptions, and the environmental benefit would be colossal. "Flight shame" is a perfect example of this, leading to a reduction on air travel and a popular trend of favouring ground transport-here, flying becomes a social embarrassment. ${ }^{12}$ Public shaming of companies, politicians and governments can also be effective, potentially influencing how people vote, and even leading to consumer boycotts- $75 \%$ of UK customers avoid or boycott products from brands that have poor environmental records. ${ }^{13}$ Second, shame holds the potential of bettering our moral agency in the context of environmental matters simply by facilitating discussion and reflection-the comparison of internal and external values - on environmental ethics. Now, I suggest that climate shame happens both as a result of intentional shaming (such as that offered in Thunberg's UN speech or carried out by environmental organisations that "name and shame" corporations with poor environmental track records), and unintentional shaming. The latter is likely the most common source of climate shame, and-again, as exemplified by "flight shame" — can occur as a result of mere implicit criticism hidden in one's own actions.

But what about the defenses linked to shame-how could a person ranting at Greta Thunberg become more environmentally aware? One solution is that the grip of defenses can be loosened. Thomason has accentuated the possibility of replacing

\footnotetext{
12 https://www.bbc.com/future/article/20190909-why-flight-shame-is-making-people-swap-planes-fortrains

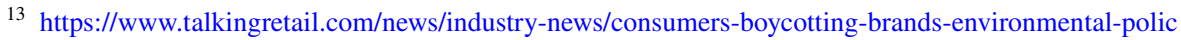
ies-kantar-reveals-04-12-2019/
} 
anger and aggression with positive actions, whereby we could regain our sense of agency-not via rage-but via, for instance, compassionate deeds (Thomason 2015). Velleman, on the other hand, has suggested that one could meet shame with humility rather than a sense of humiliation (Velleman 2001). Hence, even if defenses can occur, shame need not have destructive consequences, and with "emotion education", one can learn to meet shame in a more constructive manner capable of fostering moral growth. Thunberg could be met with compassion and humility-characteristics arguably relatively rare in contemporary debates over the climate crisis. Compassion would be directed to both those, who defend environmental values and those, who feel ashamed, whilst humility would refer to the willingness to admit that we are all only limited, faulty creatures when it comes to our de facto environmental ethics, and have much to learn and improve. We can also think of further positive emotions and characteristics that are relevant here, such as forgiveness (over deeds one has or will correct) and optimism (over one's ability to change).

Furthermore, it has been suggested that even defenses can support moral agency if a longer time-span is taken into account: one's instantaneous response to shame may be to hide or erupt into an angry, scathing rant, but after a few hours, days or weeks we may have reconsidered those issues that caused shame and make menses (Teroni and Bruun 2011). Indeed, those feeling ashamed over the climate crisis today may have a wholly different outlook next year, coloured with the willingness to alter their identity and conceptions of "selfhood" toward a direction that better incorporates environmental values. Thereby, it is quite possible that even Thunberg's loudest mockers will ultimately choose to follow her ethics, given enough time.

But how to respond to the potential psychological damage caused by shame? Some researchers distinguish shame from proneness to shame. Whereas shame as an emotion is a temporary state, shame-proneness is akin to an attitude, a type of chronic, self-criticising orientation, which pushes us to interpret events via our own presumed, inherent inadequacy (Ashby et al. 2006). One possibility is that whilst shame as an attitude (shame-proneness) can entwine with and cause mental problems, shame as an emotion is less obviously linked to psychological struggles. Following suit, it may be that whereas shame-proneness can erode moral agency, shame in itself is less harmful, leading to only momentary discomfort as opposed to chronic feelings of failure. Perhaps those most agonized by environmental criticism are prone to shame, too easily and chronically perceiving personal attacks where none are to be found. The just solution would not be to silence environmental criticism, but rather to foster a society that does not inflict individuals with the type of wounds that induce chronic shame. In other words: the problem is not shame, but the wounding realities in which we live.

Moreover, even if also the emotion of shame can momentarily feel tortuous, one argument is that one has to learn to come to terms with it. Indeed, Cheshire Calhoun has argued that tolerating shame is a sign of "moral maturity" (Calhoun 2004), which in my interpretation rests on comparing one's internal and external values reflectively. When one notices that the external, shame-provoking values are unwarranted, one can intentionally seek to eradicate the painful hold of shame; if, on the other hand, they are correct, one may learn from shame and change accordingly. As Jennifer Manion emphasizes, an important part of this process is self-compassion 
(Manion 2003, 31), whereby we approach ourselves as if we were a friend, offering gentle criticism whilst guiding ourselves toward the right direction. In all, moral maturity allows one to undergo shame without being torn into a state of psychological disarray. Applied to climate shame, one is to compare one's own values and those of the external critics, and engage in moral deliberation over which one ought to follow. If the critics are correct, the solution is to simply endure the momentary pain of shame and then to alleviate it by changing one's lifestyle in a manner that better supports the natural world. It hurts for a while, but will ease its grip as soon as we make morally reflected choices. Indeed, it seems that moral maturity is precisely what is missing in much of the public discussion over the climate crisis, as potentially ashamed instances keep lying, denying or throwing mud at others in a rather juvenile manner, leaving a 16-year-old standing as the only mature person in the room. Moral maturity should be made into "a public virtue" by accentuating its importance in, for instance, all levels of education-after all, the ability to take criticism and reflect upon it is one of the most fundamental and primary aspects of moral agency. In the context of shame, such maturity could be explicitly linked to self-compassion, whereby one was urged, not only to remain open to critics, but also to deal with their arguments without harmful self-scathing.

Yet, using moral maturity as a justification for causing shame can sound like wishful thinking, as many people lack such maturity, and the premise that it ought to be cultivated would only justify shaming in a future date, when cultivation is completed and defensiveness is no longer an issue. Moreover, there are traumatized, shame-prone people, who suffer disproportionately from shaming. Should we, then, cease shaming until moral maturity is more widely present in the society and traumas less common (a hope that may never materialize)? A deontological approach would invite us to answer in the affirmative, for as things stand, shame causes harm to given others, and causing harm is prima facie wrong. A utilitarian approach, however, leads to a different conclusion, aided by references to the "the greater good". 14 It is obvious that preventing climate change constitutes an enormous "good" — after all, the very survival of the human species, together with that of countless other species, quite probably depends on it. If shame acts as an effective pedagogic tool in combatting climate change, the weight of its utility is far greater than that of momentary individual discomfort, which justifies the act of shaming even when the ashamed will suffer. This utilitarian justification rests on the premise that defensive behavior (in the absence of moral maturity) does not, on a broader societal level, significantly reduce shame's pedagogic usefulness-in short, shaming has to be effective in causing change in behaviour.

The environmental scientist Jennifer Jacquet has argued that the box of efficacy can be ticked. According to her, in the context of climate change, guilt is commonly linked to an individualizing approach to climate change, which places the onus on the responsibility of ordinary individuals and their consumer choices. Shame, on the other hand, entwines with a social, institutional approach, which highlights the

\footnotetext{
14 I am grateful to Mikko Puumala for discussions that led me to emphasise the utilitarian approach in this context.
} 
responsibility of individuals, entities and industries with great economic and political power, and thereby acknowledges the systemic causes of and responsibilities over environmental destruction. Crucially, such highlighting is necessary if further heating is to be prevented, which positions shaming as a potentially notable tool in environmental action: things will fail to change without the type of systemic, institutional change that shame can help to ignite. Moreover, Jacquet posits that a part of shame's efficacy is found from the way in which it allows us to direct social pressure onto those climate transgressors, who escape legal punishment for their actions-in short, it stands as a tool of affecting a wider social and political change (Jacquet 2017). Here, shame's justification is found from two points: (1) due to its dependency on social image, shaming places focus on those with a high social status, and thereby hits hardest among individuals, political entities (e.g. governments) and industries that hold most power in regard to climate change, and (2) shaming allows ordinary individuals and agents (e.g. grass roots organisations) to exert influence on powerful instances. Combined with the manner in which shame, not only guilt, can also function as a pedagogic emotion on the level of ordinary individuals, these points offer support for the utilitarian conclusion: climate shaming is justified.

Therefore, although climate shame can involve ordinary individuals, they are less vulnerable to the more potent instances of shame. This is because they lack the sort of high social status that renders shame particularly commanding. Flight shame felt in front of one's friends will probably sting much less than being publically shamed for environmental destruction and having one's career or profit on the line. From the viewpoint of moral responsibility, this is significant, because it is also those with the highest status, who tend to hold most responsibility over environmental matters. Moreover, shame can be a leveler of social status and power, as it helps those with less status and power to influence the political and financial elite-indeed, climate shame can, from this perspective, be nothing less than a social equalizer.

\section{Identity and Morality}

Yet, there are further problems ahead. If shame concerns primarily social rather than moral questions and hence pushes us to focus on how others view our identity (are we successful, beautiful, rich or physically fit enough) rather than what our moral values are, would climate shame not equally revolve around questions of social standing whilst moral considerations remained superficial? Here, one could even become highly environmentally conscious merely to gain approval from others and heighten one's social standing-environmentalism would be about identity rather than ethics. One contemporary example among many can be found from the Canadian prime minister Justin Trudeau, who has been criticized for endorsing environmental action whilst building a new gas pipe. This phenomenon has become standard in marketing, where it has been named "green washing". The potential danger is that climate shame could make companies, governments and individuals evermore prone toward such identity polishing, reducing the apparent "moral change" to nothing more than corporative or personal publicity campaign. Further, due its dependency on the social dimension, shaming only works if its target's social ingroup takes, 
at least to some degree, part in shaming. If that ingroup, however, is hostile toward the values behind shaming - in the present context, if it is antagonistic toward environmental values - shame may not arise and in fact, open hostility toward those values may be socially encouraged.

Some scholars have opted for drawing a distinction between two types of shame. What is here called "identity shame" refers to shame stemming from morally irrelevant factors, such as one's aesthetic appearance or level of wealth. This variety of shame, akin to Nussbaum's "primitive shame" (Nussbaum 2004), may lead to morally destructive consequences, as one undergoes unnecessary psychological pain void of any moral lessons. It is difficult to find morally valid reasons for causing identity shame, and one can even claim that avoiding such causing is one's moral duty. "Moral shame", on the other hand, focuses on explicitly moral matters, whilst also revolving around social acceptance (Allpress et al. 2014). In a state of moral shame, we (at least upon further reflection) accept the moral norms that lead to our shame-mere social disapproval does not suffice. Thereby, moral shame includes both internal and external critique. Moreover, whereas identity shame revolves around the question of how well we have succeeded in being an acceptable "self", moral shame focuses on how have we succeeded in "moral selfhood". 15 Indeed, sociological study of shame has posited that shame may also stem from"moral identity", whereby individuals deem moral values to be a significant part of their selfhood and identity, and feel shame when failing in their moral standards (Stets and Carter 2012). Moral shame, then, emerges as a variety of shame deeply and specifically embedded in failures of our moral constitution.

Now, one possible criticism is that, due to its emphasis on moral values, moral shame is more akin to guilt than shame. Yet, there are good grounds to keep moral shame in the category of "shame". It differs from guilt by being anchored on social acceptance and selfhood, and by being self-directed. In a state of moral shame, emphasis is not on individual actions but our moral selfhood, and instead of prioritizing the wellbeing of the external world, we are highly concerned over how that selfhood appears to others. Therefore, whilst climate guilt makes one focused on actions and the outside world, climate shame motivates focus on "the self" and on how actions manifest that "self" to others.

Ideally, climate shame is a variety of moral shame. Indeed, I suggest that when we combine climate shame with moral maturity, we get "moral climate shame" as an end-result, which is the prescriptive, ideal version of climate shame, the descriptive, more common counterpart of which is "social climate shame". When it comes to social climate shame, the ashamed can disagree with the values that cause her shame. A climate change denialist can feel such shame over her environmentally destructive actions, if her own ingroup, or a sufficiently loud or socially esteemed outgroup, directs a critical spotlight on her-even when she herself does not believe in the ethics she is being judged with. With moral climate shame, the ashamed must

15 This distinction also finds its critics, who posit that shame always includes both a moral and a social dimension (Thomason 2015). 
agree (or come to agree) with the values and broader ethics that ignite her shame. She is still concerned over identity, selfhood and appearance, but with a moral twist.

I suggest that in order for shame to facilitate lasting environmental moral change, its focus must be also on moral identity instead of being limited to amoral, purely descriptive social status - a challenge met by moral climate shame. Social climate shame can lead to moral climate shame when the ashamed is provoked to reflect on her own environmental ethics, but on its own, such shame is in risk of leading to superficial instead of tangible and persistent change. For the change to be substantial rather than vacuous, we must be concerned over how well we, as individual or collective "selves", have managed to pay moral heed to other species and natural entities, and what this tells of us. Have we been just and morally wise as people (or as governments and corporations) when it comes to the way in which we treat nonhuman creatures and ecologies? Here, climate shame as a manifestation of moral shame entwines with virtue ethical questions: am I virtuous in my dealings with the environment? How could I change myself so as to become more virtuous? ${ }^{16}$

This distinction between identity (social) shame and moral shame further strengthens the moral viability of climate shame. The more excruciating dimensions of shame are arguably linked to identity shame. One can speculate on whether those, who most furiously attacked Thunberg, were in so doing revealing an amoral concern for their identity, as it is possible that they were furious simply because they felt that their high social status, and the power enmeshed with it, was under jeopardy. When individuals recoil and fume in the defenses against shame, this may be signaling that they are failing to approach shame through morality, and are instead mostly concerned for their social standing stripped bare of the moral dimensions of identity. Moreover, green washing by politicians and industries can be addressed by emphasizing morality in the context of shame-mere polishing of social appearance will not erase shame, if the underlying environmental values remain wanting. This requires that public, societal discussion on environmental ethics is made more vocal and frequent, so as to directly confront politicians' normative stance on environmental matters. Importantly, moral shame also explains why it is possible to feel ashamed even when one's social ingroup does not share the relevant values: inviting moral reflection on environmental issues can help to ignite shame out of synch with one's ingroup's anthropocentric beliefs. Here, one may be concerned with how an audience perhaps far removed from one's ingroup would morally evaluate one's actions (an example of which is a powerful politician undergoing moral shame on account of being criticized by ordinary citizens).

As long as climate shame is strongly connected to moral issues, it avoids many of the obstacles faced by identity shame. The most important is the permissibility of causing shame also from a deontological perspective. Whereas it could be even permanently scarring to the psychological wellbeing of an individual to be pushed into

\footnotetext{
16 Some may deem the mixing of utilitarian justifications with a virtue ethical account of moral growth to be problematic, but a less paradigmatic account of moral theory recognizes that often, the combination of the most constructive aspects of different theories serves moral ideals better than the strict adherence to one.
} 
a state of identity shame (and indeed, also those with high social status can fall into the spirals of even suicidal anxiety), moral shame evades such stark consequences simply because each individual can make moral changes that ease the grip of shame. Climate shame does not doom one into a permanent state of misery, but rather can be a catalyst for moral change, as the ashamed seeks to cultivate her "environmental self" by becoming more virtuous in her dealings with the surrounding reality. The psychological discomfort of shame can be eased by moral alteration. Everything depends on the person undergoing shame-whether she can meet shame through moral maturity and the development of her moral self, or whether she is primarily interested in her own, amoral standing in social hierarchies.

Ultimately, this raises the question of whether sparking climate shame could be, in given contexts, a moral duty. Thunberg was right when speaking in a fashion that ignited shame, and one could even claim that she was in so doing fulfilling a moral duty to protect the environment.

\section{Conclusion}

The urgency of the climate crisis and species extinction cannot be overstated. A broad, foundational change in industries, politics and consumer lifestyles needs to take place. Amidst this urgency, traditional moral theorizing about the environment is hopelessly ineffective. What we need more than moral theory is practical persuasion, the ability to get people to accept and follow basic environmental values and norms on the de facto level. Here, paying attention to moral psychology can be of enormous help, as one of the fundamental questions becomes: How can we make use of, for instance, emotions so as to advance moral consideration toward the environment?

This article has focused on one morally relevant emotion-shame. It has argued that "climate shame" can be a morally constructive mental state, capable of evoking holistic change in our moral outlook and lifestyles. The provocative claim is that we need more shame, and may even have the moral duty to shame those, who knowingly disregard other species and environmental flourishing. In order to minimize personal harm, such shame needs to be accompanied by references to moral maturity, which directs those undergoing shame toward moral change and allows them to note how shame can be overcome by cultivation of one's "moral self". However, even when shaming does cause personal harm, its wider utility-its capacity to affect widespread change in both individual and institutional actions and to thereby serve the planetary common good-acts as its moral justification. Here, it is important to note that climate shame concerns mostly those with most social, economic and political power, and in fact can function as an equalizing method with which ordinary individuals exert influence on the powers to be.

If catastrophic consequences are to be avoided, we as moral agents need to radically change our way of relating to the external world, and climate shame holds the potential of forming one important catalyst in such alteration. For it to become an effective emotive method and pedagogic tool of moral persuasion and change, critical and clear voices that stick to facts and moral norms without digressing into 
issues of mere amoral identity, need to become more commonplace. What the world needs is more, not less, greta thunbergs.

Funding Open Access funding provided by University of Turku (UTU) including Turku University Central Hospital.

Open Access This article is licensed under a Creative Commons Attribution 4.0 International License, which permits use, sharing, adaptation, distribution and reproduction in any medium or format, as long as you give appropriate credit to the original author(s) and the source, provide a link to the Creative Commons licence, and indicate if changes were made. The images or other third party material in this article are included in the article's Creative Commons licence, unless indicated otherwise in a credit line to the material. If material is not included in the article's Creative Commons licence and your intended use is not permitted by statutory regulation or exceeds the permitted use, you will need to obtain permission directly from the copyright holder. To view a copy of this licence, visit http://creativecommons.org/licen ses/by/4.0/.

\section{References}

Aaltola, E. (2016). Shame: From defensive fury to epistemological shifts and political change. In A. Woodhall \& G. GarmendiadaTrindade (Eds.), Ethical and political approaches to nonhuman animal issues. London: Palgrave MacMillan.

Allpress, J., Brown, R., Giner-Sorolla, R., Deonna, J., \& Teroni, F. (2014). Two faces of group-based shame. Personality \& Social Psychology Bulletin. https://doi.org/10.1177/0146167214540724.

Andrews, B., Qian, M., \& Valentine, J. D. (2002). Predicting depressive symptoms with a new measure of shame: The experience of shame scale. British Journal of Clinical Psychology, 41(1), 29-42. https ://doi.org/10.1348/014466502163778.

Ashby, J., Rice, K., \& Martin, J. (2006). Perfectionism, shame, and depressive symptoms. Journal of Counseling \& Development. https://doi.org/10.1002/j.1556-6678.2006.tb00390.x.

Calhoun, C. (2004). An apology for moral shame. Journal of Political Philosophy, 12(2), 8.

Cohen, T., Wolf, S., Panter, A., \& Insko, C. (2011). Introducing the GASP scale: A new measure of guilt and shame proneness. Journal of Personality and Social Psychology, 100, 947-966. https://doi. org/10.1037/a0022641.

Covert, M. V., Tangney, J. P., Maddux, J. E., \& Heleno, N. M. (2003). Shame-proneness, guilt-proneness, and interpersonal problem solving: A social cognitive analysis. Journal of Social and Clinical Psychology. https://doi.org/10.1521/jscp.22.1.1.22765.

Deigh, J. (1983). Shame and self-esteem: A critique. Ethics, 93(2), 225-245.

Ferguson, T., Brugman, D., Dempsey, H., \& White, J. (2007). Shame and guilt as morally warranted experiences. The Self-conscious Emotions: Theory and Research.

Fussi, A. (2015). Aristotle on shame. Ancient Philosophy, 35, 113-135. https://doi.org/10.5840/ancie ntphil20153517.

Gausel, N., \& Leach, C. W. (2011). Concern for self-image and social image in the management of moral failure: Rethinking shame. European Journal of Social Psychology, 41(4), 468-478. https://doi. org/10.1002/ejsp.803.

Gilbert, P. (2000). The relationship of shame, social anxiety and depression: The role of the evaluation of social rank. Clinical Psychology \& Psychotherapy, 7, 174-189. https://doi.org/10.1002/10990879(200007)7:33.0.CO;2-U.

Gilbert, P. (2003). Evolution, social roles, and the differences in shame and guilt. Social Research, 70(4), 1205-1230.

Gilbert, P., Allan, S., \& Goss, K. (1996). Parental representations, shame, interpersonal problems, and vulnerability to psychopathology. Clinical Psychology \& Psychotherapy, 3, 23-34. https://doi. org/10.1002/(SICI)1099-0879(199603)3:1\%3c23::AID-CPP66\%3e3.0.CO;2-O. 
Gramzow, R., \& Tangney, J. P. (1992). Proneness to shame and the narcissistic personality. Personality and Social Psychology Bulletin, 18(3), 369-376. https://doi.org/10.1177/0146167292183014.

Harari, Y. (2014). Sapiens: A brief history of humankind. London: Harper.

Irwin, H. (1998). Affective predictors of dissociation: Shame and guilt. Journal of Clinical Psychology, 54(2), 237-245.

Jacobsson, K., \& Lindblom, J. (2016). Animal rights activism: A moral-sociological perspective on social movements. Amsterdam: Amsterdam University Press.

Jacquet, J. (2017). Guilt and shame in U.S. climate change communication. Oxford: Oxford University Press.

Klaassen, J. A. (2001). The taint of shame: Failure, self-distress, and moral growth. Journal of Social Philosophy, 32(2), 174-196.

Kleres, J., \& Wettergren, А. (2017). Fear, hope, anger, and guilt in climate activism. Social Movement Studies, 16(5), 507-519. https://doi.org/10.1080/14742837.2017.1344546.

Lewis, H. (1971). Shame and guilt in neurosis. New York: International Universities Press.

Lickel, B., Schmader, T., Curtis, M., Scarnier, M., \& Ames, D. (2005). Vicarious shame and guilt. Group Processes \& Intergroup Relations, 8, 145-157. https://doi.org/10.1177/1368430205051064.

Maibom, H. (2010). The descent of shame1. Philosophy and Phenomenological Research, 80(3), 566594. https://doi.org/10.1111/j.1933-1592.2010.00341.x.

Manion, J. (2003). Girls blush, sometimes: Gender, moral agency, and the problem of shame. Hypatia, 18, 21-41. https://doi.org/10.1111/j.1527-2001.2003.tb00820.x.

Martens, W. (2005). A multicomponential model of shame. Journal for the Theory of Social Behaviour, 35(4), 399-411. https://doi.org/10.1111/j.1468-5914.2005.00283.x.

Nazarov, A., Jetly, R., Mcneely, H., Kiang, M., Lanius, R., \& Mckinnon, M. (2015). Role of morality in the experience of guilt and shame within the armed forces. Acta Psychiatrica Scandinavica, 132(1), 4-1.

Norgaard, K. (2011). Living in denial: Climate change, emotions, and everyday life. Cambridge, MA: MIT Press.

Nussbaum, M. (2004). Hiding from humanity: Disgust, shame and the law. Princeton: Princeton University Press.

Pinto-Gouveia, J., \& Matos, M. (2011). Can shame memories become a key to identity? The centrality of shame memories predicts psychopathology. Applied Cognitive Psychology, 25(2), 281-290. https:// doi.org/10.1002/acp.1689.

Poless, P. G., Torstveit, L., Lugo, R. G., Andreassen, M., \& Sütterlin, S. (2018). Guilt and proneness to shame: Unethical behaviour in vulnerable and grandiose narcissism. Europe's Journal of Psychology, 14(1), 28-43. https://doi.org/10.5964/ejop.v14i1.1355.

Sartre, J.-P. (1993). Being and nothingness. Washington: Washington Square Press.

Sheikh, S., \& Janoff-Bulman, R. (2009). The "shoulds" and "should nots" of moral emotions: A self-regulatory perspective on shame and guilt. Personality and Social Psychology Bulletin, 36(2), 213-224. https://doi.org/10.1177/0146167209356788.

Stets, J. E., \& Carter, M. J. (2012). A theory of the self for the sociology of morality. American Sociological Review, 77(1), 120-140. https://doi.org/10.1177/0003122411433762.

Tangney, J. (1992). Situational determinants of shame and guilt in young adulthood. PSPB, 18(2), 199-206.

Tangney, J. P. (1995). Recent advances in the empirical study of shame and guilt. American Behavioral Scientist, 38(8), 1132-1145. https://doi.org/10.1177/0002764295038008008.

Tangney, J. P., Miller, R. S., Flicker, L., \& Barlow, D. H. (1996). Are shame, guilt, and embarrassment distinct emotions? Journal of Personality and Social Psychology. https://doi. org/10.1037/0022-3514.70.6.1256.

Tangney, J., Stuewig, J., Mashek, D., \& Hastings, M. (2011). Assessing jail inmates' proneness to shame and guilt: Feeling bad about the behavior or the self? Criminal Justice and Behavior, 38, 710-734. https://doi.org/10.1177/0093854811405762.

Taylor, G. (1985). Pride, shame and guilt. Oxford: Oxford University Press.

Teroni, F., \& Bruun, O. (2011). Shame, guilt and morality. Journal of Moral Philosophy, 8(2), 223-245.

Thomason, K. K. (2015). Shame, violence, and morality. Philosophy and Phenomenological Research, 91(1), 1-24. https://doi.org/10.1111/phpr.12110. 
Troop, N., Allan, S., Serpell, L., \& Treasure, J. (2008). Shame in women with a history of eating disorders. European Eating Disorders Review: The Journal of the Eating Disorders Association, 16, 480-488. https://doi.org/10.1002/erv.858.

Velleman, J. D. (2001). The genesis of shame. Philosophy \& Public Affairs, 30(1), 27-52. https://doi.org/ 10.1111/j.1088-4963.2001.00027.x.

Weil, S. (2002). Gravity and Grace. London: Routledge.

Williams, B. (1993). Shame and necessity. Berkeley: University of California Press.

Wilson, J. (2001). Shame, guilt and moral education. Journal of Moral Education, 30, 71-81. https://doi. org/10.1080/03057240120033820.

Zahavi, D. (2010). Shame and the exposed self. In J. Webber (Ed.), Reading sartre: On phenomenology and existentialism. London: Routledge.

Publisher's Note Springer Nature remains neutral with regard to jurisdictional claims in published maps and institutional affiliations. 